\title{
TORNAR-SE PAIS: UMA COMPREENSÃO GESTÁLTICA DAS DIFERENTES PARENTALIDADES CONTEMPORÂNEA
}

\author{
Becoming Parents: A Gestalt understanding of the different contemporary parenting \\ Convertirseen padres: una comprensión Gestalt de la diferente paternidad contemporánea
}

ANDRESSA TAVARES E SiLVA GUALBERTo Celana CARDoso Andrade

\begin{abstract}
Resumo: Família, conceito marcante para sociedade e cultura, importante alicerce das relações interpessoais, mostra mudanças e novos modelos. A decisão em ter filhos passa a ter base na experiência e realização individual, não mais por uma necessidade de modelo de família nuclear tradicional. O estudo teve como objetivo compreender a vivência de algumas modalidades de família na decisão de ter e criar os filhos. Para tal, escolheu-se a Abordagem Gestáltica como fundamentação. A Gestalt-terapia observa o processo, uma integração que nunca se completa. A presente pesquisa investigou três modelos de famílias; monoparental, casal heterossexual e homossexual. A metodologia utilizada foi pesquisa qualitativa fenomenológica. Realizou-se entrevistas semiestruturadas, com dados analisados pelo método de Giorgi. Com as entrevistas, percebeu-se que a chegada do filho traz incertezas, interrogações, novas divisões de tarefas e renúncias por parte das famílias. Conclui-se que as famílias vivem experiências semelhantes independente do seu modelo.

Palavras-chave: Família; Parentalidade; Pesquisa qualitativa fenomenológica; Gestalt-terapia
\end{abstract}

\begin{abstract}
Family, a striking concept for society and culture, an important foundation of interpersonal relationships, shows changes and new models. The decision to have children is based on individual experience and achievement, no longer because of a need for a traditional nuclear family model. The study aimed to understand the experience of some family modalities in the decision to have and raise children. For this, the Gestalt Approach was chosen as the basis. The Gestalttherapy look at the process, an integration that is never completed. The present research investigated three families models; single-parent, heterosexual and homosexual couple. The methodology used was phenomenological qualitative research. Semi-structured interviews were conducted with data analyzed by the Giorgi method. With the interviews, it was noticed that the arrival of the son brings uncertainties, questions, new divisions of tasks and resignations on the part of the families. We conclude that families experience similar experiences regardless of their model.
\end{abstract}

Keywords: Family; Parenthood; Qualitative phenomenological research; Gestalt therapy

Resumen: La familia, un concepto sorprendente para lasociedad y la cultura, una base importante de las relaciones interpersonales, muestracambios y nuevos modelos. La decisión de tenerhijos se basaenla experiencia y los logros individuales, ya no debido a lanecesidad de un modelo tradicional de familia nuclear. El objetivo delestudiofuecomprenderla experiencia de algunas modalidades familiares enladecisión de tener y criar hijos. Con este fin, el enfoque Gestalt fue elegido como larazón de ser. La terapia Gestalt observa elproceso, una integración que nunca se completa. La presente investigacióninvestigótres modelos familiares; Padres solteros, parejasheterosexuales y homosexuales. La metodología utilizada fuelainvestigación fenomenológica cualitativa. Se realizaron entrevistas semiestructuradascondatosanalizados por el método de Giorgi. Conlas entrevistas, se notó que lallegadadelniñotraeincertidumbres, preguntas, una nuevadivisión de tareas y larenuncia de lasfamilias. Se concluye que lasfamiliasviven experiencias similares independientemente de su modelo.

Palavras-clave: Familia;Paternidad;Investigacióncualitativa fenomenológica; Terapia Gestalt

“(...) o que é insubstituível é um olhar sobre a criança”

(Kehl, 2001)

\section{Introdução}

A família é um conceito marcante na sociedade e na cultura. Não se pode negar sua importância como alicerce das relações interpessoais, pois os primeiros contatos que a pessoa tem com o outro são normalmente realizados no espaço da família. Esse contexto pode favorecer ou empobrecer a pessoa, uma vez que o indivíduo é interativo por excelência (Carmo, 2007).

De acordo com o dicionário Aurélio (2001) família significa pessoas aparentadas que vivem na mesma casa, particularmente o pai, a mãe, e os filhos; pessoas do mesmo sangue. Abbagnano (2000) define que o conceito de família é recentíssimo e 
possui relações diversas que não são redutíveis a um só conceito, princípio ou tipo. Polster (1979) caracteriza família como um sistema de objetos de amor, atribuindo importância ao vínculo. É o lugar para o qual se procura desesperadamente fugir e onde nostalgicamente se procura refúgio.

Foram diversas mudanças ocorridas na família ao longo da história ocidental, as famílias passaram cada vez mais, nessa evolução, a se basearem na afeição e na intimidade. Pode-se distinguir três grandes períodos na evolução da família. A família dita tradicional que é totalmente submetida a uma autoridade patriarcal e tem como objetivo a transmissão de um patrimônio e a busca de uma reputação, dado a importância do coletivo nas famílias. Em seguida, a família moderna, que se baseia no amor romântico e na reciprocidade afetiva, na qual o filho aparece como responsabilidade dos pais e do Estado. E por fim a família pós-moderna, uma relação entre dois indivíduos que buscam relações íntimas ou realização sexual. Essas transformações ficaram conhecidas como a crise nos referências simbólicos, haja vista os processos de mudanças nos grupos familiares e nas formas de parentesco, além das novas posições e papéis das mulheres, homens e crianças. Entretanto nada de tão dramático aconteceu, pois as famílias continuam sendo compostas e decompostas e as crianças continuam se subjetivando (Amazonas \& Braga, 2006; Mattar, 2015; Roudinesco, 2003).

Nunca existiu um único modelo de família e, hoje, principalmente, o que há são multiplicidades de famílias. As transições ocorridas nos âmbitos cultural, econômico, político e social têm afetado diretamente essa instituição. Pode-se destacar como influência na transformação das famílias as mudanças demográficas, a construção social e a dinâmica populacional dos indivíduos no espaço e no tempo - tais como a maior longevidade humana com consequente aumento da população, o que favorece mais gerações em uma família e maior número de famílias; a participação crescente da mulher no mercado de trabalho - advento das grandes guerras mundiais a princípio, como necessidade, e, depois, como valor, através dos incipientes movimentos feministas; o divórcio e as organizações familiares distintas da família nuclear tradicional; o controle sobre a procriação a partir dos anticonceptivos; as transformações ocorridas nos papéis parentais e de gênero. Não é mais possível tratar a família tradicional com pai, mãe e filhos, existem diversas configurações familiares - apenas um genitor, mães solteiras, homossexuais com filhos etc. Com o redesenhar das características e possibilidades da família, a relação de consanguinidade ou de aliança não é a única possibilidade para assegurar o exercício da parentalidade (Amazonas \& Braga 2006; Carmo, 2007; Silva \& Chaveiro, 2009).

\section{As Diferentes Parentalidades}

A parentalidade é um termo relativamente recente, que começou a ser utilizado na literatura psicanalítica francesa a partir dos anos 60 para marcar a dimensão de processo e de construção no exercício da relação dos pais com os filhos (Zorning, 2010). Nas famílias medievais o conceito de parentalidade quase não existia. Desde muito cedo a criança escapava à própria família, o que não permitia que houvesse um sentimento existencial profundo entre pais e filhos. A família era uma realidade moral e social (filhos eram contribuições dos pais para uma obra social comum), muito mais do que sentimental. Os estudos de gênero propuseram o uso do termos parentalidade para que haja um deslocamento das desigualdades e inclua qualquer tipo de relação (Mattar, 2015; Moreira \&Toneli, 2013).

Foi lançado em 2019 um Trend Report- "Pelas famílias brasileiras" - pela consultoria 65/10 em parceria com a comunidade virtual Contente. Eles começam a cartilha com a seguinte pergunta: “Quais são as caras das famílias brasileiras?” já indicando a pluralidade do país. O projeto começou pelo aplicativo Instagram em 2017 com a seguinte instrução: "Fotografe novas famílias". As mais de 2 mil fotos recebidas deixaram evidente a pluralidade familiar, e o report define um pouco os modelos de família.

De acordo com o Trend Report (2019), além da família tradicional brasileira ter mudado, ela já não é mais a maioria. Em 10 anos, a configuração homem, mulher e criança passou de $58 \%$ para $43 \%$ do total de famílias brasileiras. Essa família ficou denominada como hétero com filhos. Em seguida, com 26\% vêm as mães solos. O termo mãe solo vem para substituir o termo mãe-solteira, desvinculando a maternidade do estado civil. Esse tipo de família também pode ser conhecido como monoparental, e nesse caso enquadra os homens e seus filhos (pai solo), que conta de acordo com o IBGE (2015) com 3\% das famílias brasileiras. O terceiro tipo de família, com quase 20\%, são os casais sem filhos por opção. Com 16,4\% vem as famílias reconstituídas, casais separados que trazem os filhos do primeiro casamento, e algumas vezes escolher ter filhos do novo casamento (os meus, os seus e os nossos). Com 14\% a família unipessoal, pessoas que moram sozinhas. Outro tipo de família são as homoafetivas, cujo número não é possível ter ao certo, pois muitas famílias não se assumem assim (fenômeno ligado à homofobia). De acordo com o Reporto número declarado é 58 mil casais. Os dados começaram a ser apurados em 2015, já que esse tipo de união foi legalizado do Brasil em 2013.

Entre as novas configurações, o número de famílias uniparentais é cada vez maior, e tem, na maioria dos casos, a mãe como progenitor responsável. O termo família uniparental ou monoparental têm sido usados para designar famílias 
de um único progenitor com origem na separação, no divórcio, na viuvez, na adoção ou na ausência de um dos genitores por abandono. O aumento da configuração familiar denominada como mãe solo vem em função dos altos índices de divórcio, das opções de mulheres por terem um filho enquanto solteiras e ainda por uma gravidez indesejada que não leva mais a um casamento forçado, como levaria anos atrás (Marin \& Piccinini, 2009).

Houve também uma demanda por uma forma nova de parentalidade: Os casais homossexuais. Esse modelo de família vive um enfrentamento particular e incessante na busca do direito à normatização e normalização e na inclusão nas regras, como a autorização legal para o direito à adoção de crianças. Por um tempo, casais homossexuais que tinham filhos os traziam, em geral, de casamentos heterossexuais anteriores, isto é, os filhos faziam parte de famílias recompostas. Além da reivindicação do direito à adoção, buscam também filhos biológicos através das biotecnologias de reprodução e barrigas de aluguéis. Esse é um movimento esperado, diante do crescimento e afirmação da identidade homossexual no atual e complexo estágio civilizatório (Amazonas \& Braga, 2006; Roudinesco, 2003).

No Brasil, esse processo de normatização e normalização teve seus primeiros passos legais em 5 de maio de 2011, quando o Supremo Tribunal Federal reconheceu a união entre pessoas do mesmo sexo como entidade familiar, conforme se segue:

No mérito, prevaleceu o voto proferido pelo Min. Ayres Britto, relator, que dava interpretação conforme a Constituição ao art. 1.723 do Código Civil para dele excluir qualquer significado que impeça o reconhecimento da união contínua, pública e duradoura entre pessoas do mesmo sexo como entidade familiar, entendida esta como sinônimo perfeito de família. Asseverou que esse reconhecimento deveria ser feito segundo as mesmas regras e com idênticas consequências da união estável heteroafetiva. (Brasil, 2011)

Além da busca pela construção da própria família, ao reivindicarem o direito a filhos, os homossexuais afirmam, também, suas identidades e suas diferenças enquanto grupo, e tentam garantir o acesso a esses bens sociais. Ter filhos pode ser encarado como uma tentativa de acessar os recursos simbólicos e materiais da sociedade (Amazonas \& Braga, 2006).

Mas ainda fica a questão: O que sustenta o desejo de um homem e/ou de uma mulher no processo de transição à parentalidade? São inúmeras as causas ligadas ao nascimento de um filho. Existe o desejo atávico pela reprodução da espécie, ou pela continuidade da própria existência, com crenças a respeito de uma companhia na velhice; a busca de um sentido para a vida; a necessidade de uma valorização e de um reconhecimento social; amor pelas crianças; a reprodução tradicional do modelo da família de origem; e ainda, existem aqueles filhos que não são planejados, mas são aceitos por suas famílias, que decidem também incluí-los em suas vidas. A decisão pela reprodução passa a ter base na experiência adquirida com base na realização individual e/ou social. Tornar-se pais perpassa pela história individual de cada um dos pais, e não mais por uma necessidade de modelo de família nuclear tradicional, como no passado. É uma escolha mais reflexiva. A percepção das configurações familiares precisam darum salto qualitativo, e abandonar a visão tradicional de família - branca, heterossexual, de classe média e de apenas um casamento (Carmo, 2007; Scavone, 2001).

\section{As Parentalidades Contemporâneas em Interface com a Abordagem Gestáltica}

Seria interessante pensar a parentalidade a partir de uma abordagem que propõe um ponto de vista que embase a reflexão e o posicionamento. Para tal, escolheu-se a abordagem gestáltica como fundamentação teórica e filosófica que irá embasar o estudo. Gestalt é uma palavra alemã que significa dar forma, dar uma estrutura significante, é uma ação em curso que implica em um processo de dar forma, uma formação. A Gestalt-terapia faz parte da chamada terceira força em Psicologia, foi elaborada por Fritz Perls e seus colaboradores, e teve seu surgimento por volta de 1950 (Ginger \& Ginger, 1995).

A Gestalt-terapiapossui três teorias de base: Psicologia da Gestalt, Teoria Organísmica e Teoria de Campo. Já os fundamentos filosóficos são Humanismo, Existencialismo e Fenomenologia. Dando maior enfoque à Teoria de Campo, devido sua relevância no trabalho com família, acreditase que coisas e pessoas só são compreendidas se percebidas em uma relação com o ambiente que as cercam, e só assim a pessoa se faz compreensível. O comportamento é função do campo, que por sua vez está em constante mudança. Entende a pessoa como singular, e ao mesmo tempo inserida em um campo, ou seja, só pode ser compreendida nesse campo, nesse contexto (Andrade \& Holanda, 2019).

A Gestalt-terapia é uma terapia que dá ênfase à tomada de consciência da experiência atual - aqui e agora, que inclui o ressurgimento eventual de uma vivência antiga - e foca na percepção emocional e corporal, integrando as dimensões sensoriais, afetivas, intelectuais, sociais e espirituais. Não objetiva simplesmente explicar as origens das dificuldades da pessoa, mas experimentar possíveis soluções novas. Abandona o olhar focado em causa e efeito e passa a olhar como um processo contínuo em andamento, uma integração que 
nunca se completa. A mudança, fato decorrente da awareness, convoca a criatividade da pessoa. Mudar, então, refere-se a descobertas de respostas novas a eventos antigos. Nesta abordagem acreditase que o homem é potencialmente capaz e criador. Olhar para as novas famílias de forma criativa é ter a capacidade de renunciar à velhos padrões e se abrir às novidades. Não há como manter velhos hábitos em um viver criativo. Os sinais de saúde aparecem quando o sujeito está livre dos bloqueios ligados a padrões, valores, crenças e experiências passadas que impedem o livre fluxo do potencial criativo. A resistência à mudança surge de restrições à capacidade criativa do indivíduo em sua relação com o ambiente. Suas ações tornam-se reproduções, reações condicionadas, pouco fluidas, dificultando o intercâmbio sadio e renovador (Ginger \& Ginger, 1995; Perls, 1977; Silveira, 2005).

Deste modo, o objetivo dessa pesquisa é compreender a vivência das diversas estruturas de família na decisão de ter filhos, tendo como alicerce teórico a Gestalt-terapia. De modo mais específico, investigar o processo de decisão em ter e criar os filhos; levantar semelhanças e diferenças entre os modelos de família e identificar possíveis dificuldades enfrentadas pelas famílias. O presente estudo justifica-se pela presença, cada vez maior,das diversas configurações familiares nos consultórios de psicologia, o que pede melhor compreensão e intervenção nas mesmas em ambiente psicoterápico. A vida social e pública vem também, cada vez mais,sendo pautada por diversidade e multiplicidade, e isso leva a uma tendência à intolerância às diferenças. Nessa perspectiva, esse trabalho justifica-se pela importância social de uma reflexão sobre essas diferenças nas famílias.

\section{Método}

\section{Participantes}

Participaram desta pesquisa três modelos de famílias; uma mãe solo, um casal de pais heterossexuais e um casal de pais homossexuais. Serão identificados pelos nomes fictícios:

- Janaína, 23 anos, universitária e estagiária na área de Publicidade e Propaganda, representante da família monoparental, mãe da Fernanda de 2 anos e 5 meses. Mora com a filha e a mãe.

- Camila e Renato, 30 e 36 anos, Fisioterapeuta e Designer, respectivamente, representante da família heterossexual com filho, pais de André de 1 anos e 8 meses. Moram o casal e o filho.

- Vitor e Tomás, 35 e 28 anos, Professor de teatro e filosofia e Cabelereiro, respectivamente, representante da família homossexual com filho, pais de Gustavo de 9 anos, que foi adotado aos 6 anos, e está com a família há 3 anos. Moram o casal, o filho e a mãe de Vitor.

\section{Procedimentos}

Trata-se de uma pesquisa qualitativa, na qual trabalha com questões complexas e subjetivas que não permitem definições a priori do caminho que a pesquisa irá seguir. A atenção se volta para o específico, individual e singular. A metodologia utilizada na pesquisa foi o método fenomenológico, que busca alcançar as essências do que é pesquisado a partir do vivido, da experiência imediata, da vivência. Para isso, é necessário que o pesquisador coloque entre parênteses os conhecimentos previamente adquiridos em relação ao tema que se pesquisa (Andrade \& Holanda, 2019).

O projeto foi enviado e aprovado pela Plataforma Brasil, cujo número é 10444019.6.0000.0037. Após a aprovação, a pesquisadora entrou em contato com profissionais que atendem pelo Programa de Atendimento Comunitário (PROAC) do Instituto de Treinamento e Pesquisa em Gestalt-terapia de Goiânia que conheciam famílias que atendiam aos critérios de inclusão da pesquisa. Após coletado os possíveis participantes, foi feito o primeiro contato por telefone. Ao aceitar participar da pesquisa, foi agendado aentrevista. No caso dos casais heterossexuais e homossexuais a entrevista foi feita com os dois membros da família, separadamente, evitando possíveis constrangimentos aos casais.

Antes de iniciar a entrevista, foi explicado os objetivos da pesquisa, ressaltando a questão da confidencialidade e proteção da imagem e identidade. Foi feita a leitura detalhada do Termo de Consentimento Livre e Esclarecido (Anexo 1). Com todas as dúvidas sanadase os participantes declarado compreensãodos objetivos, das condições da pesquisa e aceitando participar da mesma, o Termo de Consentimento Livre e Esclarecido foi assinado.

A entrevista foi semiestruturada, gravada em áudio, e teve as seguintes perguntas disparadoras "Como sua família vivenciou a escolha de ter filho(s) ou filha(s)?”; "Como tem sido a criação do(s) filho(s) e/ou filha(s)?”; “Qual o papel de cada cônjuge na criação do(s) filho(s) e/ou filha(s)?”; “Quaisas semelhanças e/ou diferenças da sua família com outras de seu convívio?”; “O que você destacaria como o(s) ponto(s) mais difícil(eis) na sua família?”.

Após a realização das entrevistas, elas foram transcritas na íntegra, a fim de garantir uma releitura mais fiel do material pesquisado. Em seguida, as entrevistas foram analisadas utilizando-se o método fenomenológico de Amadeo Giorgi (2010). Este é um método que parte das descrições por escrito das entrevistas dos participantes para alcançar o vivido, suas experiências e compreender a relação com o fenômeno pesquisado. A proposta foi estabelecer um diálogo com os entrevistados, de modo a facilitar a expressão de suas experiências mais íntimas de família, buscando-se o reconhecimento dos elementos vivenciais significativos, ou seja, as unidades de sentido. 
O objetivo deste método é obter "unidades de significado", ou seja, essências contidas nas descrições e que são reveladoras do fenômeno. A partir das unidades de significado, elenca-se categorias. O método contém quatro passos básicos: 1) sentido do todo, que é a leitura geral da descrição para alcançar o sentido geral do todo; 2) discriminação de unidades significativas com base em uma perspectiva psicológica e focada no fenômeno que é pesquisado, que é a discriminação de unidades de sentido dentro da perspectiva psicológica com foco no fenômeno pesquisado; 3) transformação das expressões cotidianas do sujeito em linguagem psicológica com ênfase no fenômeno que está sendo investigado, são os insigths psicológicos contido na fala; 4) síntese das unidades significativas (categorias) transformadas em uma declaração consistente da estrutura do aprendizado, declaração consistente da significação psicológica dos fenômenos observados com relação à experiência do sujeito (Amatuzzi, 2003; Andrade \& Holanda, 2019; Giorgi, 2010).

\section{Resultados e discussão}

Do conteúdo das entrevistas foram extraídos temas comuns presentes nos discursos, o que permitiu construir categorias com basenos núcleos de sentido que emergiram da fala dos entrevistados, as quais serão descritasa seguir.

Incertezas e interrogações com a chegada de um filho.

O nascimento de um filho é considerado uma ocasião especial na vida de uma família, mas que faz com que seu cotidiano seja inegavelmente alterado. No que se refere-se às mulheres, sua rotina transforma-se em mulher-mãe-profissional. Muitas vezes, as demandas geradas pelos diversos papéis assumidos produzem conflitos, obrigando-a a lidar com dilemas para conciliá-los (Andrade, 2015). Nesse contexto, surgem dúvidas e questionamentos com a chegada de um filho, que ficam claros nas seguintes falas das mães entrevistadas:

Quando eu recebi a notícia? Eu chorei horrores, achei que não era capaz, que não tava pronta ainda. Foi desespero! Eu chorei, achei meio... é o medo né! - Camila.

A primeira pessoa que eu avisei, e a primeira reação que eu presenciei quando eu falei que estava grávida, foi da minha mãe, e foi dela assustada por eu ter filha nova sabe? Mas ter filha aos 20 anos não é igual, antigamente as pessoas tinham filhos mais novas, então não foi tão assustador pela idade, mas sim por eu ainda estar estudando, pela dificuldade. Então ela só disse, ficou questionando a respeito do problema, a dificuldade de criar. - Janaína.
Nos dois casos a gravidez não foi planejada, e isso gerou uma primeira reação de susto e preocupação com a criação do filho, pois ainda é fato que, mesmo com as mulheres ocupando gradativamente o espaço público e o mercado de trabalho, elas mantêm a responsabilidade na criação dos filhos. Neste contexto, ser é mãe é influenciado por fatores relacionados às condições subjetivas, econômicas e sociais das mulheres, e torna a maternidade um dilema para as mulheres que querem seguir uma carreira profissional, o que por muitas vezes provoca um sentimento de sobrecarga com o acúmulo de funções. (Andrade, 2015; Scavone, 2001).

No que se refere aos homens, também há incertezas com a chegada de um filho, Tomás afirma que “(...) o começo, quando chega, a gente estranha um pouco, porque é uma criança, aí o que que eu vou fazer! Se sentir dor, ai meu Deus do céu!Antes atrelada à divisão sexual do trabalho, a paternidade se voltava à capacidade de prover financeiramente a família, independentemente da relação concreta do pai com seus filhos. Atualmente, o leque de atributos que integra a paternidade cresceu, em especial no que diz respeito ao tema do cuidado, e há um esforço em implementar uma noção de que homens podem e devem cuidar, e que o cuidado aos filhos lhes faz bem. Deste modo, os pais, como Tomás deixa claro, também vivem comdúvidas e incertezas, pois em tempos modernos compartilham espaço na criação e assumem responsabilidades com essas crianças. A partir do momento que os homens saem do lugar de provedores financeiros e assumem o lugar de pai responsável, as incertezas chegam até eles (Moreira \&Toneli, 2013).

E quando a parentalidade se dá por meio de um processo de adoção outras incertezas entram em pauta, com incertezas que se referem ao próprio processo de conseguir a guarda da criança:

(...) tem hora que me dá muito medo, muita ansiedade. Eu ligo para o advogado toda hora, 'ah, o que que eu vou falar para o juiz? Como é que vai ser? E se ele fizer alguma pergunta que eu não souber responder?'- Vitor

Os pais adotantes estão sujeitos a longos períodos de espera entre o momento que decidem pela adoção até o momento em que ela efetivamente ocorre. Esse processoéfrequentementeacompanhado de episódios de intensa ansiedade, como no caso de Vitor relatado acima (Levinzon, 2004).

Independentemente da forma que essa criança vem para família - planejada, não planejada, adotada - o campo da pessoa e/ou do casal é alterado. A Teoria de Campo, uma das bases teóricas da Gestalt-terapia acredita que as pessoas não existem independente do seu campo psicológico, elas estão no campo, e são definidas pelo campo o qual fazem parte (Yontef, 1998). Ou seja, um filho é parte do campo dos pais, e 
qualquer movimento da pessoa é determinado pelo campo, assim, ser pai é incluir um elemento no seu campo para sempre, e saber que esse elemento vai contribuir na sua definição de pessoa.

\section{A divisão de tarefas entre pais hetero e homossexuais.}

Foi possível perceber nos relatos dos participantes que há um desequilíbrio entre o papel do pai e da mãe na criação dos filhos, isso para as famílias heteroafetivas. A tarefa de cuidar das partes práticas (saúde, alimentação, higiene, rotina) e da educação é de responsabilidade das mães, cabendo aos pais uma tarefa mais financeira, ligada ao sustento da família. A mãe faz e o pai ajuda. Quando sobra tempo ou quando há algum problema com a mãe, o pai entra nessa ajuda nos cuidados. É possível perceber esse funcionamento nas falas dos entrevistados:

No começo era mais eu, eu que ficava o dia inteiro com ele, eu que trocava, dava banho. Ainda faço mais coisas, igual, eu que abro mão de parar de trabalhar 17 h30 da tarde para ficar com ele. Então nesse período eu que dou banho, eu que dou comida, e eu que boto para dormir. Mas como o Renato chega tarde em casa, geralmente ele já está dormindo, mas, quando ele não está dormindo, aí o Renato faz dormir. - Camila.

Igual, mamadeira até hoje ele não sabe fazer também, mas se eu falo 'ah coloca tantos $\mathrm{mLs}$ de água e tantas colher de leite', aí ele faz, ou quando eu tô muito cansada, eu dô uns pitis e aí ele faz. - Camila.

Por mais que eu tente ser muito presente, ainda existe um resquício social e de um monte de coisa que o peso da criação ainda recai um pouco sobre a mãe. (...) a própria mãe tipo, toma muito para ela a responsabilidade. - Renato.

Os papéis dos pais no exercer da parentalidade apresentaram transformações com o passar dos anos. O nascimento de um bebê significava estado de dependência absoluta dele para com a mãe nos primeiros meses de vida, conceito esseque vem mudando, pois passa a ser compartilhado com o pai. Entretanto, Camila destaca na sua fala que no começo ficava com mais responsabilidades no cuidado do filho e que Renato vai assumindo mais, mas o que não significa uma divisão equilibrada de tarefas, Camila ainda faz mais. O exercício da parentalidade se apresenta com uma nova roupagem, mas no interior da sociedade e das famílias segue as premissas do pensamento patriarcal tradicional onde o cuidado maior recai sobre o lado materno. O cuidado da casa e dos filhos permanece como responsabilidade principal da mulher, ao passo que o provimento financeiro é visto ainda como responsabilidade primordial dos homens, por mais que haja tentativa de fazer diferente (Amazonas \& Braga, 2006, Andrade, 2015).Essa mudança que não se efetiva por estar presa às raízes do patriarcado fica clara na fala de Renato:

Me sinto muito cobrado nessa questão financeira, acho que as coisas financeiras não vão bem aqui em casa, acaba vindo como uma cobrança social também, então acho que a gente acaba assumindo esses papéis, tentando assumir esses papéis. Por mais que eu queria tá mais com o André, queria tá curtindo mais, vivenciar mais as coisas dele, muitas vezes eu tô tipo igual eu tô agora, estafado, muito cansado, e às vezes eu não aproveito do tanto que eu queria, saca? Essa é uma parte meio difícil de lidar.

Apesar das mudanças, avanços e transformações, sair dos modelos mais cristalizados de família ainda é um desafio; ir além do homem provedor financeiro, protetor do núcleo familiar, autoridade moral e mulher mantenedora do lar e suporte afetivo da família parece ser hoje mais um movimento de busca do que, de fato, um ponto já chegado. Tendo em vista que em Gestalt movimento significa saúde e consciência pode-se então considerar esse movimento das famílias por si só positivo. O fato do pai, nesse caso Renato, perceber os entraves que sente para ir além do padrão já é por si só uma experiência positiva, e que movimenta, de alguma forma, o sistema familiar (Moreira e Toneli, 2013).

Aí ele [o pai] pega um final de semana sim e outro não, paga pensão de acordo com que foi designado lá pelo juiz, mas nada além disso, se eu tiver um médico um exame ele não paga. Se a Fernanda tiver alguma emergência é função minha. Então ele é pai de final de semana. - Janaína.

Já no caso de Janaína, a mãe solo, mesmo com as garantias judiciais e com o acordo com o pai, a carga de responsabilidade maior segue sendo dela. Observa-se uma particularidade maior no caso da mãe solo, que além dos papéis de gênero e suas respectivas funções, lida com a ausência até da ajuda. Essa organização familiar tende a exigir recursos adaptativos, visto que aspectos relacionados à ausência do pai têm sido apontados como importantes para o desenvolvimento familiar e, consequentemente, para a criança. No âmbito do Direito essa ausência paterna foi reconsiderada no Estatuto das Famílias (2014), que assegurou a pensãoalimentícia compensatória, e considerou conduta ilícita o abandono afetivo de um dos pais com o filho. 
O desequilíbrio relatado acima não aparece nas famílias homoafetivas. O que fica com as entrevistas é uma divisão de tarefas e responsabilidades mais justa e tranquila, sem ter o peso maior para uma das partes, que pode ser observado nas falas:

Não é sempre, mas por exemplo assim, o Vitor leva e busca na escola. Eu sou mais a função assim, o Vitor trabalha a tarde, aí o Gustavo não pode ficar sozinho, aí eu tenho que trazer ele para o trabalho. Na função de roupa, de cortar cabelo, cuidar mais assim sou eu. Mas, levar na escola, buscar, ir em reunião, é mais o Vitor. - Tomás.

Eu que levo na escola, o Tomás leva para cortar o cabelo. Quando vai sair quem escolhe as roupas é o Tomás. Vai comprar roupa ele já sabe que o Tomás que compra. Mas, ele sabe que cozinhar tanto um quanto o outro cozinha (...). - Vitor.

Uma possível explicação para essa divisão mais equilibrada nas relações homoafetivasestá na questão de gênero. Ainda que tenha evoluções e a mulher conquistado seu espaço na sociedade, muitos papéis são atribuídos especificamente a elas nas suas famílias. Pensando então na paternidade apenas masculina, não haveria uma diferenciação de funções por gêneros, já que não há o lugar do homem e o lugar da mulher, e sim o lugar de pais e o que cada pai sabe fazer melhor (Moreira \&Toneli, 2013).

\section{As renúncias da parentalidade em diferentes modelos de família.}

A chegada de um filho exige da família novas estratégias para lidar com as tarefas, capacidade de adaptação para receber o novo membro e habilidades para administrar as necessidades emergentes do sistema (Desen e Braz, 2000). Tomás relata partes práticas na adaptação que leva a renunciar certa praticidade e simplicidade da vida antes do filho:

Quando você é solteiro assim, quando você é um casal que não têm criança, você não preocupa com fazer comida, você pode comer qualquer coisa que tá bom, com criança não. Criança tem hora para comer, hora para dormir, horário para acordar, horário para assistir televisão, tem horário para tudo. Então, cria uma rotina e você tem que ficar sempre atento a outra pessoa que precisa de você. Como ele vai fazer uma comida? Ele não dá conta! Então aí você assimila que agora sou eu e mais um, sou eu e mais dois. Por exemplo, sou eu, o Vitor e o Gustavo. Qualquer criança é dependente, então quando chega, meu Deus agora essa responsabilidade é nossa, uma responsabilidade muito grande. Quando chega a gente dá uma assustadinha, mas depois vai indo. - Tomás.
Para Tomás o peso da criação está na responsabilidade em cuidar, e como isso altera o campo e a rotina da família. Assumir um filho, tornar-se responsável por uma criança, significa renunciar parte de sua autonomia pessoal (Moreira \&Toneli, 2013). As mães entrevistadas também relatam sobre o peso que enfrentam, que no caso delas está intimamente ligado ao sentimento de perda de autonomia:

É cansativo, o cansaço. A gente tá cansado o tempo inteiro! No meu caso, pegou muito a questão da liberdade. Eu perdi muito da minha liberdade, tipo assim, eu adorava tomar um café no final do dia, não existe isso mais. Às vezes eu quero sair com o Renato, aí tem que organizar muito bem, e tem muitas vezes que a gente não vai sair porque não tem com quem deixar. - Camila

(...) mães não podem ir para palestra, porque a Fernanda é totalmente minha quando não estou trabalhando ou estudando, então se eu tiver que fazer um workshop, eu preciso levar ela. Aí quando eu vou em workshop, todo mundo olha pra você como se você não deveria estar ali, a mãe não pertence... a mãe com filho não pertence a sociedade, por mais que todo mundo acha bonitinho uma criança, mas a criança tem que colocar no seu lugar. - Janaína

A família, como totalidade buscará a melhor forma possível de se organizar, sempre em buscada autorregulação por meio de ajustamentos criativos. Há famílias que lidam de forma satisfatória com suas necessidades de equilíbrio, o que leva a um funcionamento mais saudável entre seus membros. Por outro lado, há famílias que alcançam formas pouco ou parcialmente satisfatórias, o que fazcom que um ou mais membros sacrifiquem seu próprio funcionamento saudável em prol da manutenção da dinâmica familiar (Aguiar, 2015). Com as entrevistas observa-se, respectivamente, um funcionamento saudável e equilibrado e outro com mais sacrifícios e peso:

Então é muito bom, eu fico muito, muito feliz! É corrido! E eu acho que eu encarnei muito a coisa, então, por exemplo, eu não me importo de falar assim, 'ah, não vou fazer tal coisa porque eu não posso levar o Gustavo, ou eu preciso ficar com o Gustavo' isso para mim não tem peso nenhum. (...) Eu por mim eu não importo, eu prefiro sabe? Ficar lá quietinho em casa com ele, ou sair com ele. - Vitor.

Eu fico bem cansado, mas, ela sempre argumenta 'ah, mas eu também tô cansada' e tal. Tipo, mas, eu não sei assim, existe o cansaço do compromisso, 
existe outro cansaço, sabe, não sei explicar isso, também é um assunto bem delicado, enfim, eu acho que isso tem pesado muito, essa coisa de tipo, eu não poder parar hora nenhuma. Então isso tem sido um peso assim, que tem prejudicado um pouco as coisas. - Renato.

Nos dois casos os entrevistados relatam que ser pai representa exercer várias atividades ("É corrido"; "não poder parar hora nenhuma”), Entretanto, observa-se que para Vitor as possíveis renúncias não causam peso, e que suas adaptações foram feitas de maneira mais saudáveis. Já para Renato o cansaço da paternidade parece pesar mais. Os dois estão fazendo ajustamentos, mas Renato parece estar ajustando de forma mais disfuncional na tentativa de organizar a estrutura familiar. Autorregular envolve a capacidade de respeitar a totalidade funcional do organismo, significa olhar-se e comportar-se com organização e privilegiar as necessidades que mais precisam ser satisfeitas, e o ajustamento criativo seria encontrar as soluções disponíveis para se autorregular. Encontrar caminhos que não sejam tão pesados, que não prejudiquem o fluxo da família promove uma relação mais saudável para pais e para filhos (Ribeiro, 2006). Ou seja, a literatura gestáltica acredita que as famílias tem potenciais para se autorregularem e se desenvolverem de maneiras mais criativas, mesmo que isso signifique abrir mão de algumas coisas. Não é que não exista renúncia, mas elas podem ter um teor menos pesado para os pais.

\section{Toda família é família: as semelhancas que perpassam nos modelos de família.}

A parentalidade envolve uma situação subjetiva que acaba não dependendo, necessariamente, da configuração da família. Não há um único modelo de família que possa ser considerado como padrão familiar saudável e ideal, ou um muito nocivo e impossível. As necessidades das crianças podem ser supridas por uma variedade de rearranjos sociais e ajustamentos criativos. O que parece ser mais importante é que todos aqueles que contribuem para o desenvolvimento das crianças tenham recursos emocionais, sociais e materiais adequados para este fim. Os afetos sobrepõem-se e transcendem os códigos sociais, o que dá sustentabilidade às relações e ganho de sentido para suportar as dificuldades naturais do convívio familiar (Marin \& Piccinini, 2009). Os participantes da entrevista concordam com o exposto acima, e destacam que o tipo de família não determina sucesso ou fracasso:

Assim ... eu vejo diferença na educação, mas não é questão de ser mãe solteira ou filhos criados com vó. Eu vejo diferenças de criações de todos os jeitos, sabe? Independente de família. - Camila.
(...) eu não tenho parâmetro, não conheço tantas pessoas com outros modelos de família assim para poder julgar. Se a pergunta for moralmente falando eu acho que não. Eu não acho que modelos diferentes causam algum prejuízo na criação ou alguma coisa assim, saca? É ... eu não consigo ter uma opinião muito formada por desconhecer um pouco sabe, mas de longe, de um pouco que eu já vi, que eu conheço, eu acho que não tem diferença. Um exemplo de família que eu tenho é meu primo, que foi criado por nossa tia, e puts, ele cresceu exemplar, então não era um modelo convencional, porque minha tia é casada com uma mulher e enfim, ele não foi adotado por ela, mas ele foi criado, então é um exemplo muito positivo que eu vi. - Renato.

De acordo com o Estatuto das famílias (2014) nenhum ramo do Direito sujeitou-se a tantas alterações e avanços quanto o Direito de Família ocidental. O uso do plural para identificar este ramo do Direito não é por acaso, vem como a melhor forma de contemplar as novas configurações familiares, que deixaram de ser singular e passaram a ser plural. O projeto de lei surgiu da percepção da impossibilidade de tratar questões da vida familiar, que perpassam por idealizações, sentimentos e perdas, valendo-se das mesmas normas que regulam questões meramente patrimoniais. A Constituição atribui a todas as entidades familiares a mesma dignidade, sendo merecedoras de igual tutela, sem hierarquia, e no seu Art. $3^{\circ}$ destaca que a família é protegida em qualquer de suas modalidades e as pessoas que a integram. A lei traz como entidades familiares o casamento, a união estável, a família parental, na qual se inclui a família monoparental e a pluriparental e as famílias que se constituem com egressos de vínculos afetivos anteriores, famílias recompostas. Quanto às uniões homoafetivas, o Direito das Famílias não faz tratamento destacado. Ao invés de se falar em "homem e mulher", a referência é feita a "duas pessoas".

A jurisprudência reconhece os novos paradigmas parentais, em outras palavras, as mais diversas formas de parentalidade, e trata de modo igualitário as relações de filiação, independente se de origem consanguínea ou socioafetiva. A adoção, a posse de estado de filho e a inseminação artificial são exemplos de que a família é uma realidade socioafetiva, e ressalta no Art. $9^{\circ}$ que o parentesco resulta da consanguinidade, da socioafetividade e da afinidade. Nas duas entrevistas com os representantes da família homoafetiva fica claro a naturalidade que falam da sua família, enfrentando dificuldades e sucessos como qualquer outra família, o que é possível perceber na fala de Tomás: “Assim, eu não vejo muita diferença. Ás vezes pode ter na cabeça das outras pessoas que veem de fora né, como que dois homens criam uma criança? Mas, 
para mim é super tranquilo.”. Vitor compartilha da mesma percepção:

Nenhum. Olha, vou te falar, eu tenho contato com muitas famílias héteros, por exemplo, que é o que a gente conta como mais referência, não tem nenhuma. Eu falo por causa da minha irmã, por causa da Joana (nome fictício) que tem minha afilhada, e de outras famílias. Eu tenho o Wagner (nome fictício) e a Verônica (nome fictício), que é uma família assim, eles eram dois casais, cada casal tinha três filhos, e eles eram casais amigos, aí a mulher desse casal se apaixonou pelo o homem desse casal, e vice e versa. Hoje eles são separados e têm dois filhos, entendeu? Eles convivem. São as mesmas questões, (...) assim, questões padrões de família, e que são super parecidos com os meus, super, super! - Vitor.

Há algumas hesitações quanto aos modelos de família que saem do padrão casal heterossexual com filhos, e uma delas é a concepção de que a criança não teria a transmissão da ideia da existência da diferença anatômica dos sexos, faltaria a vivência do papel masculino - no caso de mães solteiras ou homo afetividade feminina - ou a vivência do papel feminino - no caso de pais solteiros ou homo afetividade masculina. O primeiro ponto que refuta essas teses é que haverá outras pessoas na vivência da criança, não só os pais, como avós, tios, professores, amigos da família, entre outros. Em segundo lugar, todo ser humano é herdeiro de uma história, mas, ao herdá-la não necessariamente irá vivê-la ou aceitá-la tal como é. Os filhos de homossexuais, do mesmo modo que os demais filhos, terão que conviver com suas heranças, fazendo suas próprias escolhas. Isso já quebra outro tabu da parentalidade homossexual, a de que os filhos também serão homossexuais por influência. Se assim fosse, casais heterossexuais sempre teriam filhos heterossexuais. Em uma perspectiva existencial, a criança não é um adulto em miniatura ou uma semente que se desenvolverá em fases, mas a criança tem um espaço que lhe é próprio. Pensar a criança é considerar a peculiaridade e as possibilidades que se mostram em seu horizonte, vêla com inúmeras possibilidades de desenvolvimento e formação de personalidade (Amazonas \& Braga, 2006; Feijoo, Protásio \& Gill, 2015).

Sob a ótica gestáltica as famílias podem ser vistas como bem-sucedidas, independentemente de sua configuração familiar, pois acredita-se nas potencialidades do humano, na sua criatividade, competências na interação e na sua liberdade de escolha. É importante o estabelecimento de relações familiares envolvendo amor, proximidade e cooperação, bem como a busca pela superação conjunta de dificuldades. A definição de família saudável não é necessariamente congruente com o modelo de família tradicional nuclear. $\mathrm{O}$ que confere um caráter saudável não são os elementos constituintes em si, mas sua configuração, os lugares ocupados na dinâmica familiar e as funções estabelecidas. Esse bom funcionamento depende também de como os integrantes conseguem fazer encontros saudáveis na fronteira do "eu" e na fronteira do "nós" (Aguiar, 2015; Marin \& Piccinini, 2009; Silveira, 2005).

Em suma, a família na sua intimidade está tentando criar/educar seus filhos. Criar inclui o atendimento às necessidades básicas, materiais e emocionais da criança - alimentação, higiene, sono, carinho, atenção. Educar vem no sentido de ensinar, transmitir valores, princípios, atitudes e conhecimentos universais, e a busca desse ideal deve estar em qualquer modelo de família (Monteiro \& Cardoso, 2001). Janaína representa bem esse ideal, e necessariamente o desafio da parentalidade na sua fala: "Assim, a gente está tentando criar um filho (risos) essa é a semelhança.".

\section{Considerações Finais}

As novas famílias passam sim por dificuldades e produzem sintomas, mas esses, por sua vez, estão muito relacionados à dívida geracional e histórica em relação a um modelo de família supostamente ideal e perfeito: a família da modernidade perdida (na realidade nunca encontrada, pois nunca existiu), ou seja, não se pode falar que as famílias têm problemas pelos seus modelos e membros que a integram. Essa dívida deixa de herança uma sobrecarga que impede que os pais e mães atuais se autorizem e se encarreguem de acolher, criar e educar as crianças que lhes cabem, que são de sua responsabilidade, seja qual for a maneira pela qual elas foram atribuídas a eles, seja qual for a sua origem. Aparece aqui uma grande ambivalência que a cultura social prega para o fenômeno da parentalidade: Ser diferente e não agir "como nossos pais" mas, contraditoriamente, escutar o tempo todo que as famílias e as crianças atuais são mais problemáticas do que as antigas, e assim forçar esses pais à seguir o ideal modelo antigo. É necessário sair da singularidade em direção ao caleidoscópio de aspectos que desenha, concebe, e, consequentemente, vivem as famílias (Kehl, 2001; Monteiro \& Cardoso, 2001; Paro, Machado \& Oliveira, 2001).

Ainda que hajam todas essas transformações e constantes rearranjos no interior da família, pode-se dizer que ela ainda se mantém idealizada e desejada. A família, não importa a configuração que assuma, continuará a existir, pois é o que pode assegurar à criança, aos novos sujeitos que se apresentam ao mundo, o direito ao amor, ao acolhimento no mundo humano e à palavra. A função da família envolve acolher, satisfazer e proteger seus membros, assim como frustrar, aceitar as diferenças e facilitar o desenvolvimento da autonomia.Viver em contato, 
caminhar juntos na complementaridade da vida são instrumentos fundamentais de sobrevivência (Aguiar, 2015; Amazonas e Braga, 2006).

Diante disso, fica claro a importância de estudar e pesquisar a família em todas as suas formas, compreender melhor suas particularidades e semelhanças, e assim possibilitar melhores intervenções terapêuticas, escolares e nos demais contextos que as famílias possam estar inseridas, pois “(...) a família é o único valor seguro ao qual ninguém quer renunciar" (Roudinesco, 2003, p. 198). E ainda que hajam incertezas, inseguranças, conflitos e renúncias, a experiência de família e do cuidado com o outro, no caso um filho, não é apenas sinônimo de privações e obrigações, esta pode ser vivida também como algo prazeroso na vida de homens e mulheres.

É preciso acreditar nas famílias, e essa pesquisa traz voz a três modelos de família e elucida que há possibilidades em todas elas. Não se dá fim à investigação acerca das famílias nessa breve pesquisa. Existem outros inúmeros modelos de famílias possíveis de serem estudados - família reconstituída, casais que optam por não ter filhos, família de um integrante, mães solos na fertilização e adoção, pais solos, avós, tios e irmãos que assumem a criação, e por aí vai - este estudo é apenas um ponto de partida para reflexões mais amplas e novas pesquisas. Seria interessante entrevistar os mesmos modelos de famílias em outros estados do Brasil, para ver se há uma diferença e/ou avanços culturais. Outra possibilidade seria pesquisaros diferentes modelos de família dando voz às crianças, como elas percebem suas famílias. E ainda uma terceira possibilidade seria refazer as entrevistas com os participantes do presente estudo para levantar se houve mudanças nas percepções após um tempo.

\section{Referências}

Abbagnano, N. (2000). Dicionário de filosofia. $4^{\mathrm{a}}$ ed. São Paulo, SP: Martins Fontes.

Aguiar, L. (2015). Gestalt-terapia com crianças: teoria e prática. São Paulo: Summus.

Amatuzzi, M. M. (2003). Pesquisa fenomenológica em psicologia. In Bruns, M.A.T. Holanda, A. F. \& (orgs.) Psicologia e Fenomenologia: Reflexões e perspectivas (pp.17-25). Campinas, SP: Alínea.

Andrade, C. C. (2015). Maternidade e trabalho na perspectiva de mulheres e seus companheiros: um estudo empírico fenomenológico. ix, $259 \mathrm{f}$., il. Tese (Doutorado em Psicologia Clínica e Cultura). Universidade de Brasília: Brasília - DF.
Andrade, C. C.,\& Holanda, A. F. (2019). A pesquisa qualitativa e a pesquisa fenomenológica. Sentidos da psicoterapia: Teoria e prática da Gestalt-terapia (pp. 23-42). Curitiba, PR: Juruá.

Amazonas, M. C. L. A., \& Braga, M. G. R. (2006). Reflexões acerca das novas formas de parentalidade e suas possíveis vicissitudes culturais e subjetivas. Ágora: Estudos em Teoria Psicanalítica, 9(2),177-191. doi: 10.1590/ S1516-14982006000200002

Brasil. (2014). Estatuto das Famílias. PLS 470/2013.

Brasil. (2011) RE 643229.Divulgada 06 de setembro de 2011. Publicada 08 de setembro de 2011.

Carmo, M. (2007). Configurações familiares - um novo paradigma. Revista da Abordagem Gestáltica, 13(2), 260-262. Goiânia, GO.

Contente \& 65/10 (2019). Trend Report. Retirado de: http://www.pelasfamilias.com.br/23/

Dessen, M. A. \& Braz M. P. (2000). Rede social de apoio durante transições familiares decorrentes do nascimento de filhos. Psicologia: Teoria e Pesquisa, 16(3), 221-231. Brasília, DF.

Feijoo, A. M. L. C.,Protasio, M. M.,\& Gill, D. (2015). Considerações sobre o desenvolvimento infantil em uma perspectiva existencial. In Feijoo, A. M. L. C \&Feijoo, E. L. Ser criança: Uma compreensão existencial da experiência infantil (pp. 13-34). Rio de Janeiro: Edições IFEN.

Ferreira, A. B. H. (2001). Mini Aurélio século XXI escolar: O minidicionário da língua portuguesa. $4^{\mathrm{a}}$ Ed. Rio de Janeiro: Editora Nova Fronteira.

Ginger, S. Ginger, A. (1995). Um primeiro olhar sobre a Gestalt. Gestalt uma terapia do contato. (pp. 13-20). São Paulo: Summus.

Giorgi, A. (2010). Sketch of a psychological phenomenological Method, In C. Aanstoos, W. F. Fischer, A. Giorgi \& F. J. Wertz (org). Phenomenology and psychological research. (pp. 8-22). Duquesne University Press: Pittsburgh, PA.

Kehl, M. R. (2001) Lugares do feminino e do masculino na família. In Comparato, M.C.M. Monteiro, D.S.F. (org.). A criança na contemporaneidade e a psicanálise. São Paulo: Casa do Psicólogo.

Levinzon, G. K. (2004). A espera para adotar. Adoção (pp. 13-18). São Paulo: Casa do Psicólgo

Marin, A. \&Piccinini, C. A. (2009). Famílias uniparentais: A mãe solteira na literatura. Psico, 40(4),422-429. Porto Alegre, RS. 
Mattar, C. M. (2015) A criança e a família: Aspectos históricos e dilemas contemporâneos In Feijoo, A. M. L. C \&Feijoo, E. L. Ser criança: Uma compreensão existencial da experiência infantil (pp. 13-34). Rio de Janeiro: Edições IFEN.

Moreira, L. E. \&Toneli, M. J. F. (2013). Paternidade Responsável: problematizando a responsabilização paterna. Florianópolis, SC.

Paro, C. R., Machado, M. C. S. P. \& Oliveira, M. L. M. (2001). Perfil da família goianiense In Sousa, S. M. G. \&Rizzini, I. Desenhos de família-criando os filhos: a família goianiense e os elos parentais (pp. 395-468). 10. Ed. Porto Alegre: Cânone Editorial.

Perls, F. (1977) Introdução.Gestalt-terapia explicada. 2. ed. (pp. 13-83). São Paulo: Summus.

Poster, M. (1979). Teoria crítica da família. Rio de Janeiro: Zahar Editores S.A.

Ribeiro, J. P. (2006). Vade-mécum de Gestalt-terapia: Conceitos básicos. São Paulo: Summus.

Roudinesco, E. (2003). A família em desordem. Rio de Janeiro: Jorge Zahar.

Scavone, L. (2001) Maternidade: Transformações na família e nas relações de gênero. Interface, Comunic, Saúde, Educ, 5(8), 47-60. Araraquara, SP.

Silva, M.C. \& Chaveiro, E. F. (2009). Demografia e família: As transformações da família no século XXI. Boletim Goiano de Geografia, 29(2), 171183. Goiânia, GO.
Silveira, T. M. (2005). Caminhando na corda bamba: Agestalt-terapia de casal e de família.IGT. Retirado de https://www.igt.psc.br/Artigos/caminhando na corda bamba.htm

Yontef, G. M. (1998). Introdução à teoria de campo. Processo, diálogo e awareness. (pp.173-212). 3 Ed. São Paulo: Summus.

Zorning, S.M.A-J. (2010). Tornar-se pai, tornar-se mãe: O processo de construção da parentalidade. Tempo Psicanalítico, 42(2),453-470. Rio de Janeiro, RJ.

Andressa Tavares e Silva Gualberto, Pontifícia Universidade Católica de Goiás. Email: andressa. tsilva2@gmail.com.

Celana Cardoso Andrade, Universidade Federal de Goiás

Recebido em 14.05.2020

Aceito em 16.04.2021 